Ciência e Natura, Santa Maria, v. 37 n.42 set-dez. 2015, p. 756-766

Revista do Centro de Ciências Naturais e Exatas - UFSM

ISSN impressa: 0100-8307 ISSN on-line: 2179-460X

\title{
Potencial de geração de biogás a partir da suplementação de óleo de babaçu em dejetos de animais
}

\author{
Potential of biogas generation from babassu oil supplementation in livestock manure
}

Marluce Lumi ${ }^{1}$, Odorico Konrad ${ }^{1}$, Josmar Almeida Flores ${ }^{2}$, Munique Marder ${ }^{1}$, Lorenzo Zorzi ${ }^{2}$

Centro de Ciências Exatas e Tecnológicas, UNIVATES.

Pós-Graduação em Ambiente e Desenvolvimento, UNIVATES

\begin{abstract}
Resumo
O uso de oleaginosas para fins energéticos em comunidades isoladas que não possuem acesso às redes convencionais de distribuição de energia elétrica está sendo bastante discutido, uma vez que há vasta disponibilidade destas biomassas na Região Amazônica e poucas atividades econômicas sustentáveis em torno da mesma. Dessa forma, o trabalho objetivou avaliar o comportamento e o potencial de geração de biogás através da mistura de dejetos de bovinos, suínos e aves quando suplementado com óleo de babaçu nos percentuais de 2,5\%,5,0\% e 7,5\%. O estudo foi desenvolvido no Laboratório de Biorreatores do Centro Universitário UNIVATES, sendo a avaliação da geração de biogás realizada através de um dispositivo baseado no deslocamento de fluidos e na equação combinada dos gases ideais, enquanto o teor de metano contido no biogás foi verificado através de um sensor específico para este fim, denominado Advanced Gasmitter. Os resultados obtidos demonstram que a aplicação de óleo de babaçu $(O B)$ em resíduos agrícolas melhora o rendimento de biogás e de metano, sendo que o tratamento suplementado com $7,5 \%$ de $O B$ o qual obteve melhor desempenho.
\end{abstract}

Palavras-chave: Energia renovável, biogás, digestão anaeróbia, desenvolvimento sustentável.

\section{Abstract}

The use of oil for energy in isolated communities that lack access to conventional grid electricity distribution is being widely discussed, since there is wide availability of these biomass in the Amazon region and few sustainable economic activities around it. Thus, the study aimed to evaluate the behavior and the potential for biogas generation through the blend of cattle manure, swine and poultry supplemented with babassu oil (2.5\%, 5.0\% and 7.5\%). The study was developed at the Bioreactors Laboratory of University Center UNIVATES, and the assessment of biogas generation achieved by a device based on the displacement of fluids and combined equation of ideal gases, while the methane content contained in biogas has been verified through a specific sensor for this purpose, called Advanced Gasmitter. The results obtained show that the application babassu oil $(O B)$ in livestock manure improves the yield of biogas and methane. The treatment supplemented with $7.5 \%$ of $O B$ got the better performance.

Keywords:Renewable energy, biogas, anaerobic digestion, sustainable development. 


\section{Introdução}

$\mathrm{F}$ ontes renováveis de energia a partir de biomassa, representam potencial de crescimento no cenário mundial por serem consideradas as principais alternativas para diversificação da matriz energética e, redução da dependência do uso de combustíveis petrolíferos.

No contexto energético, a biomassa é toda matéria orgânica proveniente de origem animal ou vegetal que pode ser utilizada na produção de energia (ANEEL, 2015). Moret e Guerra (2012) consideram a biomassa um importante insumo de uso energético, pois desenvolve a sustentabilidade local por meio da geração de energia e renda através do aproveitamento dos subprodutos.

Além disso, destacam o potencial do uso de oleaginosas como babaçu, buriti, tucumã, dendê, e andiroba para fins energéticos em comunidades isoladas da região Amazônica, uma vez que há vasta disponibilidade destas biomassas e poucas atividades econômicas sustentáveis em torno da mesma.

O conceito de sustentabilidade local é de fundamental importância em comunidades isoladas onde predomina o extrativismo, como por exemplo, no interior da região Amazônica, a qual não possui acesso às redes convencionais de distribuição de energia elétrica devido à baixa densidade populacional e à extensão das redes que geralmente é ambientalmente e economicamente inviável (CENBIO, 2003).

Para Rizzo e Pires (2005), o padrão de desenvolvimento econômico está intimamente ligado ao padrão energético, sendo que para a escolha de um novo modelo de suprimento de energia (térmica, elétrica, combustível veicular) deve ser considerado o impacto sobre o meio ambiente, a disponibilidade de recursos e os custos.

A utilização de fontes renováveis para a geração de energia elétrica deve ser orientada numa perspectiva que contribua positivamente nos aspectos socioambiental, econômico e político. Nessa mesma perspectiva, a geração descentralizada de energia é promissora para que seu uso seja mais democratizado, agregue emprego e renda local, com justiça ambiental e social (MORET, 2004).

A energia elétrica, segundo Moret (2004) é "um fator estruturante da sociedade, pois define e influencia os aspectos econômicos, financeiros, sociais, ambientais, culturais e políticos, sendo estratégica para todos os tipos de sociedades". Nesta lógica, torna-se necessária a busca e o incentivo por tecnologias que promovam o aproveitamento energético de fontes renováveis com o intuito de desenvolver a sustentabilidade.

A falta de energia elétrica limita 0 desenvolvimento de atividades que promovem emprego e renda, acarretando na exclusão social (VELÁZQUEZ et al., 2014). Desta forma, o suprimento de energia elétrica para comunidades isoladas é uma maneira de melhorar as condições de vida e isto pode dar-se pela geração de biogás através do processo de digestão anaeróbia da biomassa disponível.

Segundo Börjesson e Berglund (2006), esta tecnologia caracteriza-se como um meio produtivo que resulta na obtenção de benefícios ambientais, apresentando-se como alternativa que pode suprir a demanda energética de comunidades isoladas, promovendo gestão sustentável por meio da autossuficiência energética e melhoria da qualidade de vida em reservas extrativistas.

O babaçu é uma biomassa florestal não madeireira caracterizada como um dos principais recursos extrativistas do Brasil, de fundamental importância social, cultural e econômica (NOLETO, 2012). Abrange entre 13 a 18 milhões de hectares no Brasil e, vem sendo utilizado como biomassa para produção de biodiesel e transformado em carvão, não sendo realizados estudos que viabilizem o uso desta biomassa para fins de geração de energia através de biogás (NOLETO, 2012).

Neste sentido, o presente trabalho objetivou avaliar o potencial de geração de biogás utilizando uma mistura de dejetos de bovinos, de suínos e de aves quando suplementados com óleo de babaçu nos percentuais de 2,5\%, 5,0\% e $7,5 \%$. 


\section{Materiais e Métodos}

O estudo foi desenvolvido no Laboratório de Biorreatores do Centro Universitário UNIVATES, onde a avaliação da geração de biogás foi realizada por meio de metodologia desenvolvida pelo próprio laboratório.

Os reatores foram armazenados em incubadora e acoplados a um sistema automatizado de medição de biogás, composto por um coletor de vidro em forma de U, um sensor óptico, uma esfera de isopor e um circuito eletrônico que registra a passagem do biogás pelo sistema (Figura 1).

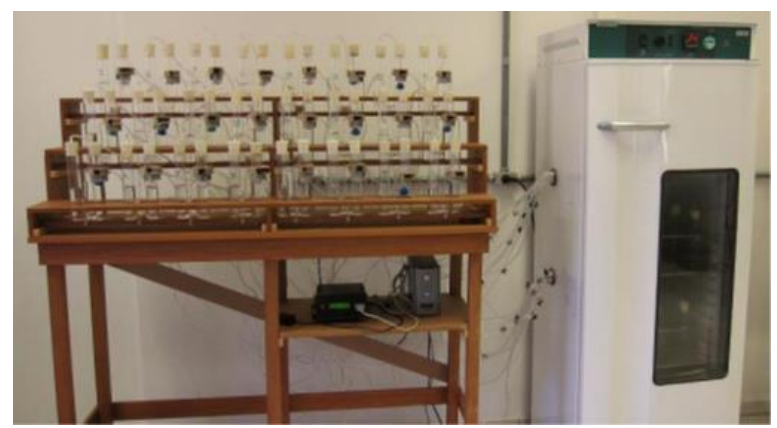

Figura 1: Sistema automatizado de medição de biogás.

O funcionamento do dispositivo baseia-se no deslocamento de fluidos, sendo a quantificação do biogás realizada quando o mesmo, à medida que enche um dos lados dos tubos em $\mathrm{U}$, desloca o fluido nele contido (água) e eleva o nível do fluido no lado oposto. Esta etapa detectada por um sensor óptico, envia a informação para um circuito eletrônico e armazena sob forma de "eventos".

A quantificação do biogás é determinada pela equação combinada dos gases ideais (Equação 1), sendo a relação entre a temperatura, pressão e volume de um gás constante (HALLIDAY et al. 2009).

$$
\frac{P 1 V 1}{T 1}=\frac{P 2 V 2}{T 2}
$$

(Equação 1)

Para tanto, é feita calibração do sistema antes do início dos experimentos, considerando a pressão, temperatura e volume do momento da calibração.

Quando ocorre o "evento", o sensor óptico mensura a pressão e a temperatura no instante da passagem do biogás, sendo possível determinar o volume de biogás gerado.
A concentração de metano contida no biogás foi verificada diariamente através de um sensor específico para este fim, denominado Advanced Gasmitter, produzido pela PRONOVA Analysentechmik GmbH \& Co.

O co-substrato utilizado (óleo de babaçu) foi obtido junto à Reserva Extrativista do Rio Ouro Preto pertencente ao Estado de Rondônia. Foi necessário a realização de cadastro no Sistema de Autorização e Informação em Biodiverdidade (SISBIO) pertencente ao Instituto Chico Mendes de Conservação da Biodiversidade (ICMBio), a fim de solicitar autorização para atividades com finalidade científica (Protocolo de autorização $\mathrm{n}^{\mathbf{o}}$ 46.454).

O substrato utilizado consiste em uma mistura de dejetos de bovino (70\%), dejetos suínos $(30 \%)$ e dejetos de aves $(20 \%)$, coletados em uma pequena propriedade na Linha Forqueta em Arroio do Meio/RS (Figura 2). Os dejetos de bovino e de suíno foram coletados diretamente das esterqueiras, enquanto o dejeto de ave foi coletado em um poleiro e por estar muito seco, precisou ser diluído em água (1:1). Mora-Naranjo et al., (2004) e Pommier et al., (2007) ressaltam a importância do uso da água em processos de digestão anaeróbia, uma vez que a água tem a capacidade de dissolver e difundir nutrientes e substrato para o meio poroso de alimentação das bactérias.

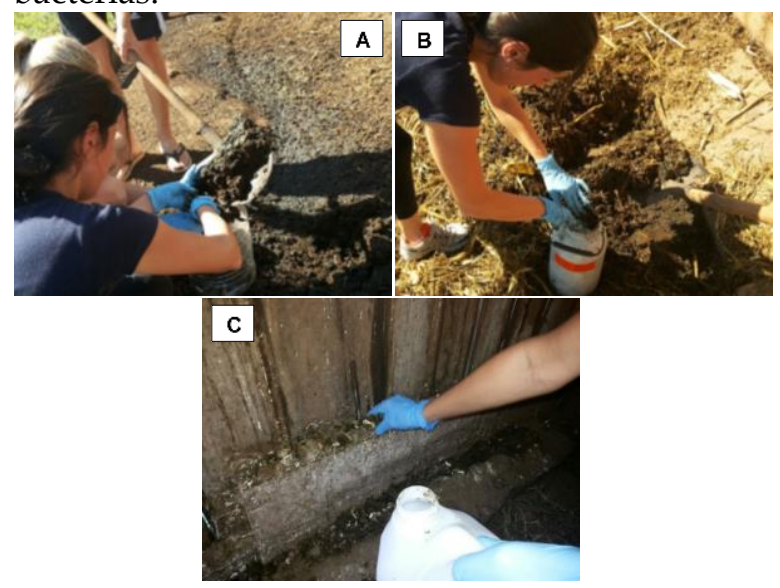

Figura 2: Coleta dos substratos. A) dejeto suíno; B) dejeto bovino; C) dejeto de aves.

Para realização do teste foram utilizados vinte reatores em batelada contendo $500 \mathrm{~g}$ de substrato, os quais foram acondicionados em incubadora com temperatura constante de $35{ }^{\circ} \mathrm{C}$, o que caracteriza o processo anaeróbio como mesofílico. Os doze reatores que apresentaram maior representatividade e uniformidade na 
geração de biogás foram escolhidos para serem suplementados com óleo de babaçu (OB) nos percentuais de 2,5\%, 5,0\% e 7,5\% em relação ao volume total de amostra, sendo a dosagem realizada em cinco momentos distintos (semanalmente e em horário específico). Para comparação dos resultados, preparou-se uma amostra controle $(0 \% \mathrm{OB})$.

As amostras foram caracterizadas antes e após o processo anaeróbio através de análises de Carbono Total, Nitrogênio Total Kjeldahl, pH, Sólidos Totais, Sólidos Voláteis e Sólidos Fixos, de acordo com a Tabela 1.

Tabela 1: Parâmetros físico-químicos conforme metodologia e equipamento.

\begin{tabular}{ccc}
\hline PARÂMETRO & METODOLOGIA & EQUIPAMENTO \\
\hline Nitrogênio Total & PHA/AWWA (1995) & $\begin{array}{c}\text { Bloco digestor de 8 provas } \\
\text { Destilador de nitrogênio }\end{array}$ \\
\hline Carbono Total & PHA/AWWA (1995) & Chapa aquecedora \\
\hline $\mathrm{pH}$ & - & pHmetro \\
\hline $\begin{array}{c}\text { Sólidos totais, } \\
\text { voláteis e fixos }\end{array}$ & AOAC (1995) & $\begin{array}{c}\text { Estufa microprocessadora } \\
\text { Mufla microprocessadora }\end{array}$ \\
\hline
\end{tabular}

Realizou-se a análise estatística dos resultados obtidos através da análise de variância pelo teste de comparação de médias de Tukey $(\mathrm{P}<0,05)$. Foram considerados quatro tratamentos e três repetições para cada um deles. Utilizou-se correlação paramétrica de Pearson para analisar a relação entre o volume de biogás e o volume de metano.

\section{Resultados e Discussões}

\subsection{Análises físico químicas}

O poder calorífico superior (PCS) do óleo de babaçu foi analisado pelo Laboratório de Análises Físico-Químicas da Embrapa, enquanto o poder calorífico inferior (PCI) foi obtido na literatura (ARAUTERM, 2015), sendo respectivamente de $9.092 \mathrm{kcal} / \mathrm{L}$ e 7.770
kcal/L. Os demais parâmetros estão expostos na Tabela 2:

Tabela 2: Caracterização do óleo de babaçu (OB) e do substrato.

\begin{tabular}{c|cc}
\hline Parâmetros & OB & Substrato \\
\hline $\mathrm{pH}$ & 5,80 & 7,60 \\
$\mathrm{C}(\mathrm{mg} / \mathrm{L})$ & - & $52.215,46$ \\
$\mathrm{~N}(\mathrm{mg} / \mathrm{L})$ & - & $1.199,61$ \\
Relação C/N & - & 43,53 \\
ST & $98,44 \%$ & $24,03 \%$ \\
SV (\% ST) & $98,40 \%$ & $10,40 \%$ \\
SF (\% ST) & $0,04 \%$ & $13,64 \%$ \\
\hline
\end{tabular}

Observa-se na Tabela 3 os parâmetros físico químicos avaliados após 122 dias de tratamento anaeróbio e na Tabela 4 o percentual de remoção/aumento.

Tabela 3: Parâmetros físico químicos avaliados após 122 dias de biodigestão.

\begin{tabular}{c|cccc}
\hline Parâmetros & $\mathbf{0 \%}$ OB & $\mathbf{2 , 5 \%}$ OB & $\mathbf{5 , 0} \%$ OB & $\mathbf{7 , 5 \%}$ OB \\
\hline $\mathrm{pH}^{*}$ & 7,75 & 7,80 & 7,91 & 7,85 \\
$\mathrm{C}(\mathrm{mg} / \mathrm{L})$ & $29.965,84$ & $33.475,42$ & $41.998,28$ & $31.833,39$ \\
$\mathrm{~N}(\mathrm{mg} / \mathrm{L})$ & $2.848,25$ & $2.162,67$ & $3.812,54$ & $3.004,32$ \\
Relação C/N & 10,52 & 15,48 & 11,02 & 10,60 \\
Sólidos Totais (ST) & $15,93 \%$ & $15,57 \%$ & $17,86 \%$ & $17,21 \%$ \\
Sólidos Voláteis (\% ST) & $7,50 \%$ & $7,37 \%$ & $7,90 \%$ & $8,12 \%$ \\
Sólidos Fixos (\% ST) & $8,42 \%$ & $8,20 \%$ & $9,96 \%$ & $9,08 \%$ \\
\hline
\end{tabular}

* Temperatura: $25^{\circ} \mathrm{C}$. 
Tabela 4: Remoção e aumento dos parâmetros físico químicos nas amostras suplementadas com óleode babaçu $(\mathrm{OB})$ em comparação à amostra $0 \%$.

\begin{tabular}{c|ccc}
\hline Parâmetros & $\mathbf{2 , 5 \%}$ OB & $\mathbf{5 , 0} \%$ OB & $\mathbf{7 , 5 \%}$ OB \\
\hline C (mg/L) & $+11,71 \%$ & $+40,15 \%$ & $+6,23 \%$ \\
N (mg/L) & $-24,07 \%$ & $+33,86 \%$ & $+5,48 \%$ \\
Relação C/N & $+47,13 \%$ & $+4,71 \%$ & $+0,71 \%$ \\
Sólidos Totais (ST) & $-2,23 \%$ & $+12,15 \%$ & $+8,04 \%$ \\
Sólidos Voláteis (\% ST) & $-1,76 \%$ & $+5,27 \%$ & $+8,27 \%$ \\
Sólidos Fixos (\% ST) & $-2,65 \%$ & $+18,27 \%$ & $+7,84 \%$ \\
\hline
\end{tabular}

* Remoção (-); Aumento (+)

$\mathrm{O} \mathrm{pH}$ do substrato ficou próximo da neutralidade, enquanto a faixa de $\mathrm{pH}$ das amostras após o processo anaeróbio ficou entre 7,75 e 7,91 (Tabela 3). Anderson e Yang (1992) relatam que a faixa ideal de $\mathrm{pH}$ para que não ocorra inibição em função do acúmulo de ácidos graxos voláteis (AGV) deve ser entre 6,4 e 7,6.

Tais valores indicam que o $\mathrm{pH}$ nos reatores propiciou a geração de biogás. Deve-se considerar o teor de alcalinidade do substrato, quando são adicionados co-substratos com baixo $\mathrm{pH}$, para que não ocorra queda de $\mathrm{pH}$ no meio, o que pode afetar, primeiramente, a atividade metanogênica (SILVESTRE et al., 2015).

A relação ótima de $\mathrm{C} / \mathrm{N}$ para o processo de digestão anaeróbia) deve ser de 15 a 30, no entanto existem referências que indicam que a melhor relação $\mathrm{C} / \mathrm{N}$ para atividade metanogênica ocorre entre 16 e 19 (MSHANDETE et al., 2004; KIVAISI e MTILA, 1998). A relação $\mathrm{C} / \mathrm{N}$ da amostra afluente deste estudo foi de aproximadamente $43 / 1$, ou seja, superior a recomendada. Quanto a relação $\mathrm{C} / \mathrm{N}$ após a biodigestão, constata-se que a amostra suplementada com $7,5 \%$ OB obteve o melhor desempenho, uma vez que em relação a amostra $0 \% \mathrm{OB}$, foi a que apresentou o menor aumento. Neste sentido, não pode-se afirmar que maiores concentrações de OB acarretam no aumento da relação $\mathrm{C} / \mathrm{N}$, a não ser que o processo tenha, em algum momento, se desestabilizado. Observa-se no estudo de Konrad et al., (2014), que a relação $\mathrm{C} / \mathrm{N}$ aumentou à medida que foi aumentado o percentual de co-substrato (glicerina residual) adicionado ao sistema.

Constata-se que em relação a amostra afluente (substrato) os reatores suplementados com 2,5\% OB foram os que apresentaram maior remoção de sólidos totais (ST) e voláteis (SV), a qual foi de aproximadamente $35 \%$ e $40 \%$, respectivamente (Tabela 4). Isto pode ser justificado pelo fato da baixa carga orgânica adicionada ao sistema que foi facilmente assimilada pelos microrganismos e que o cosubstrato utilizado acelerou o processo de degradação (KONRAD et al., 2013). Destaca-se também que os ST aumentaram à medida que foi adicionada maior carga orgânica ao processo, $\mathrm{o}$ que também foi observado por Konrad et al., (2014). Com relação à amostra que não recebeu as suplementações de OB, verifica-se que a maior remoção também foi obtida com a dosagem de $2,5 \%$ OB.

\subsection{Geração de biogás}

A Figura 3 ilustra o comportamento da geração diária de biogás e na Figura 4 a concentração de metano ao longo do período de experimentação. 


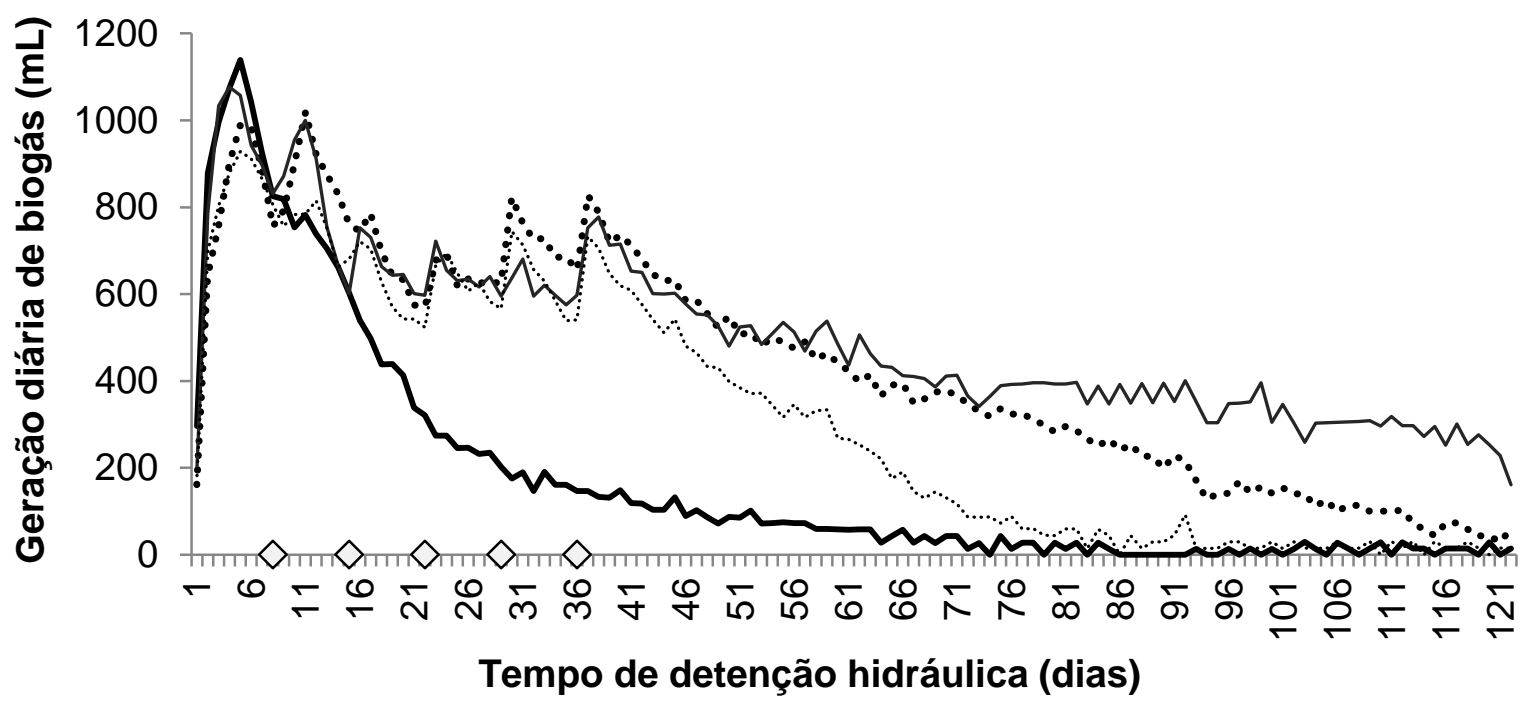

$-0 \%$ OB $\cdots \cdots \cdot 5,0 \%$ OB $-7,5 \%$ OB $\cdots \cdots \cdots \cdots \cdots . . . .2,5 \%$ OB $\diamond \quad$ Adição de OB

Figura 3: Comportamento do biogás gerado diariamente das amostras $0 \%, 2,5 \%, 5,0 \%$ e 7,5\% OB com tempo de detenção hidráulica de 122 dias.

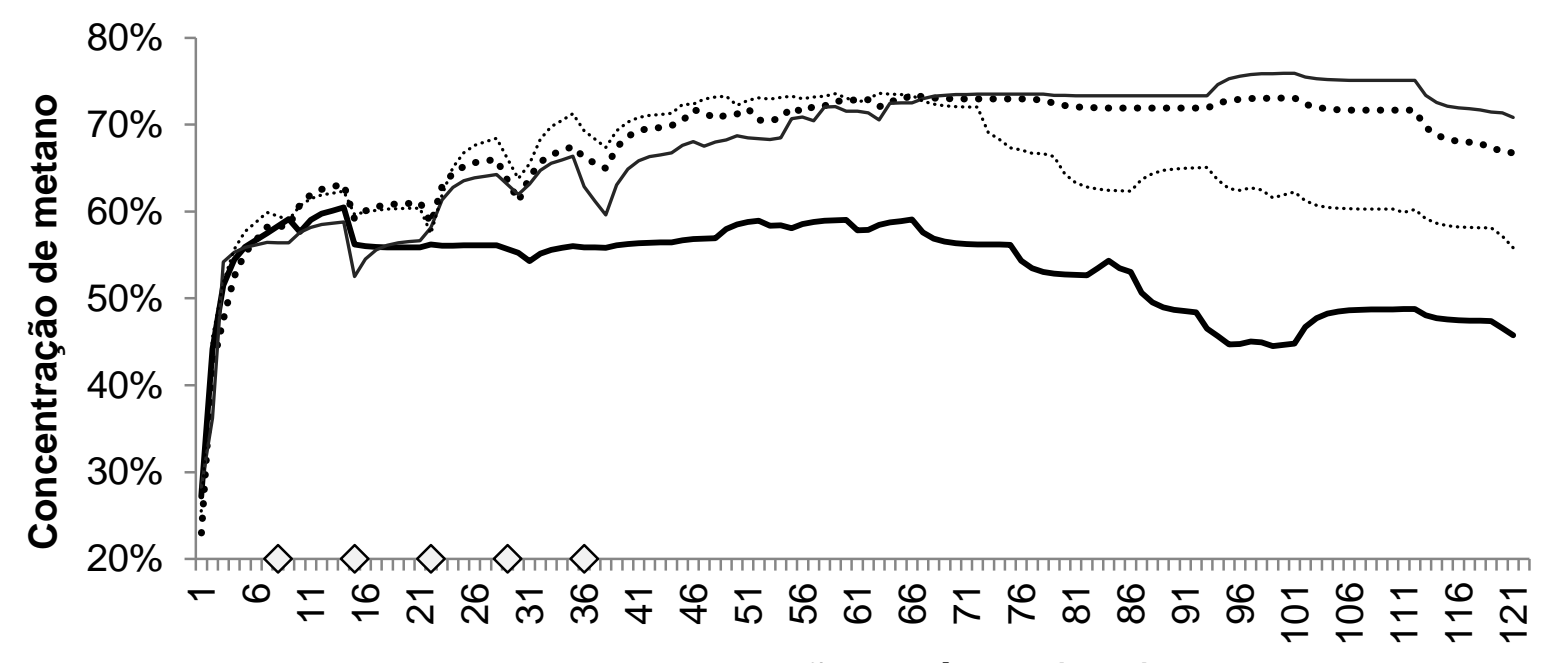

Tempo de detenção hidráulica (dias)

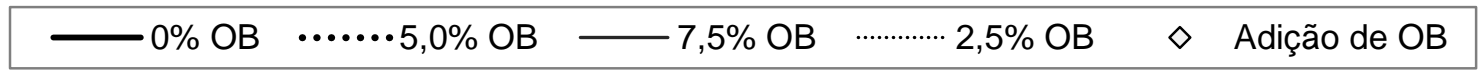

Figura 4: Comportamento da concentração de metano das amostras 0\%, 2,5\%, 5,0\% e 7,5\% OB com tempo de detenção hidráulica de 122 dias.

Nota-se que o pico de biogás na amostra $0 \%$ $O B$ se deu na primeira semana de experimentação, mostrando constante decréscimo até cessar a produção. É importante destacar que, inicialmente, a concentração de metano foi aumentando à medida que crescia a geração de biogás, estabilizando-se em torno de $55 \%$ durante aproximadamente trinta dias, atingindo o teor mínimo de $44 \%$ no $100^{\circ}$ dia de experimentação. A geração média de biogás da amostra $0 \%$ OB foi de 176,22 $\pm 273,32 \mathrm{~mL}$.dia com concentração de metano de 53,50 $\pm 5,19 \%$.

$\mathrm{O}$ grupo que recebeu dosagens de $2,5 \% \mathrm{OB}$ obteve carga orgânica adicional total de $12,5 \mathrm{~mL}$ ao fim das cinco suplementações e apresentou geração de 320,52 $\pm 296,16 \mathrm{~mL}$.dia de biogás, com teor de metano de $64,90 \pm 6,83 \%$. Observa-se que nenhuma aplicação de OB resultou em picos de 
biogás superiores à primeira semana de experimentação e que os maiores teores de metano se deram entre a $3^{\underline{a}}$ e $4^{\underline{a}}$ aplicação de $\mathrm{OB}$, a qual se estabilizou entre $70 \%$ e $73 \%$ após a última dosagem durante aproximadamente 30 dias.

Quanto ao comportamento da geração de biogás do grupo que recebeu dosagens de 5\%, verifica-se que no período que corresponde às suplementações de OB tiveram-se as maiores oscilações na concentração de metano, sendo que o teor do mesmo estabilizou em cerca de $70 \%$. Após o término das dosagens, notou-se queda de $5 \%$ na última semana de experimentação. Ao final de 122 dias este grupo obteve 439,03 \pm 269,30 mL.dia de biogás e teor de metano de $67,94 \pm 7,07 \%$, onde a suplementação total de OB correspondeu a $25 \mathrm{~mL}$.

O grupo suplementado com 7,5\% OB recebeu $37,5 \mathrm{~mL}$ de $\mathrm{OB}$ e gerou diariamente 439,03 \pm 269,30 mL de biogás com concentração de metano de 67,78 \pm 8,08\%. Observa-se que este grupo foi o que apresentou maior estabilidade na geração de biogás e alcançou os maiores teores de metano. Assim como nos demais grupos suplementados, nenhuma dosagem de OB resultou em pico de geração de biogás superior ao pico inicial, sendo que as quedas nas concentrações de metano também acontecerem durante o período de suplementações.

Astals et al., (2012) relatam aumento de 400\% na geração de biogás durante a biodigestão de dejeto suíno suplementado com $4 \%$ de glicerina e evidenciaram que esta é a concentração limite para manter um processo de digestão anaeróbia estável. Konrad et al., (2014) também estudaram o comportamento da digestão anaeróbia de dejetos suínos quando suplementados com glicerina residual e obtiveram melhores resultados em rendimento de biogás e de metano com dosagens de 6\%.

Konrad et al., (2013) aplicaram óleo de cozinha residual em lodo de estação de tratamento de efluentes e evidenciaram que a melhor dosagem foi a de $9 \%$, embora a adição de
6\% tenha representado maior estabilidade na relação entre biogás e concentração de metano.

Assim como nos estudos de Konrad et al., (2013) e Konrad et al., (2014), a concentração de metano apresentou queda após a adição de cosubstrato, no entanto observa-se que o óleo de babaçu não resultou em quedas bruscas como nas suplementações de glicerina, se assemelhando aos resultados obtidos pela suplementação de óleo vegetal residual. Comparando os co-substratos utilizados nestes estudos com o óleo de babaçu, é evidente que tanto o óleo vegetal residual como o óleo de babaçu são degradados com maior facilidade, não resultando em toxicidade ou inibição do processo quando comparados à suplementação com glicerina residual.

Gelegenis et al., (2007), avaliaram o potencial de geração de biogás de dejeto de aves e de suínos suplementado com efluente resultante da produção de óleo de oliva nos percentuais de $25 \%, 30 \%$ e $50 \%$ e constataram que o rendimento de biogás aumentou à medida que aumenta a fração de óleo suplementada. Todavia, a amostra que recebeu $50 \%$, apresentou maior instabilidade e, consequentemente diminuição drástica da geração de biogás, enquanto a fração correspondente a $30 \%$ apresentou melhores resultados com teor de metano em $65 \%$.

O comportamento da geração de biogás e de metano obtido com a suplementação de óleo de babaçu não corroboram com os resultados da pesquisa de Razaviarani et al., (2013), uma vez que os autores obtiveram produção máxima de biogás com a adição de 1,0\% e 1,1\% de glicerina, com aumento de $113 \%$ e $87 \%$, respectivamente, na produção de metano, sendo que a concentração limite de glicerina foi de $2 \%$. Acima disto, foi verificada uma diminuição considerável na geração de metano. Da mesma forma, Fountoulakis et al. (2010), obtiveram um processo instável com alta concentração de AGV no sistema ao suplementar glicerina no percentual de $3 \%$. 


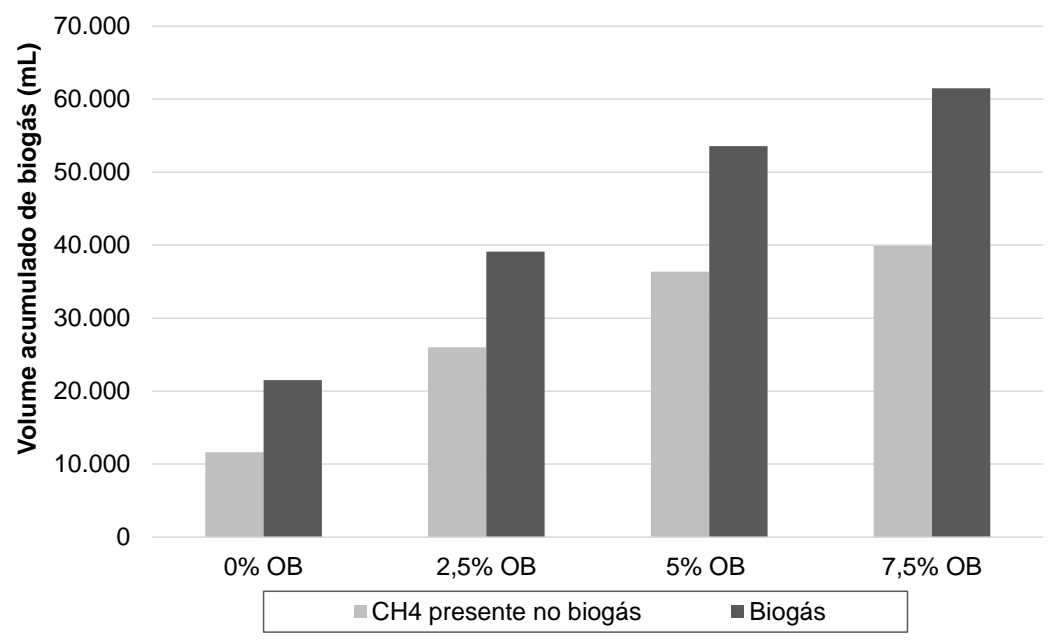

Figura 5: Geração acumulada de biogás e de metano das amostras 0\%, 2,5\%, 5\% e 7,5\% OB.

Em relação a amostra controle $(0 \%$ OB $)$ verificou-se que o grupo que recebeu $7,5 \%$ de $\mathrm{OB}$ obteve maior rendimento de biogás e de metano, o qual foi de, $285 \%$ e $341 \%$, respectivamente, seguido da amostra $5 \%$ OB que obteve incremento de $248 \%$ no volume de biogás e de $311 \%$ no volume de metano quando comparado a amostra $0 \%$ OB (Figura 5).

Embora as concentrações limites de cosubstrato divergirem bastante dos outros estudos aqui apresentados, verifica-se que a dosagem de co-substrato eleva a produção de metano e isto pode estar associado ao crescimento da biomassa que é ativada no momento em que é introduzida alguma fonte de carbono. Neste sentido, aumenta a capacidade de degradação de cargas orgânicas e consequentemente, a taxa máxima de metano (Fountoulakis et al., 2010; Ma et al., 2007; Mata-Alvarez et al., 2011). No entanto, Sun et al., (2014) e Zhang et al., (2013) alertam que elevados teores de óleo podem limitar a taxa de biodigestão e resultar na acumulação de resíduos de óleo no sistema.

Os resultados obtidos corroboram com a conclusão do estudo realizado por Saidu et al., (2014), evidenciando que a co-digestão anaeróbia impulsiona a produção de biogás, alcançando desempenhos estáveis de digestão anaeróbia. Além disso, assim como constatado no estudo de Neves (2009), os óleos (lipídeos), quando adicionados ao processo aumentam a produção de metano, além de serem completamente degradados.

Os dados obtidos referentes à geração de biogás foram submetidos à análise de variância e quando apresentando diferenças significativas, aplicou-se o teste de comparação de médias de Tukey $(\mathrm{p}<0,05)$.

Tabela 5. Comparação de médias do volume de biogás e de metano através do teste de Tukey.

\begin{tabular}{|c|c|c|}
\hline Tratamento & Biogás & $\mathrm{CH}_{4}$ \\
\hline $0 \%$ OB & a1 & a1 \\
\hline $2,5 \% \mathrm{OB}$ & a2 & a2 \\
\hline $5,0 \% \mathrm{OB}$ & a3 & a3 \\
\hline $7,5 \%$ OB & a3 & a3 \\
\hline
\end{tabular}

Nas colunas "Biogás" e " $\mathrm{CH}_{4}$ ", letras seguidas pelo mesmo número não diferem estatisticamente.

Em relação ao volume de metano e de biogás gerado, todas as amostras suplementadas com $\mathrm{OB}$ diferenciaram-se da amostra controle $(\mathrm{O} \%$ $\mathrm{OB})$, no entanto os grupos $5,0 \%$ e $7,5 \%$ não diferenciaram-se estatisticamente entre si, embora tenha-se observado incremento de $248 \%$ e $285 \%$, respectivamente, na geração de biogás e de $311 \%$ e $341 \%$ no volume de metano.

Utilizou-se a correlação de Pearson para analisar a relação entre o volume de biogás e o volume de metano, conforme Figura 6. 

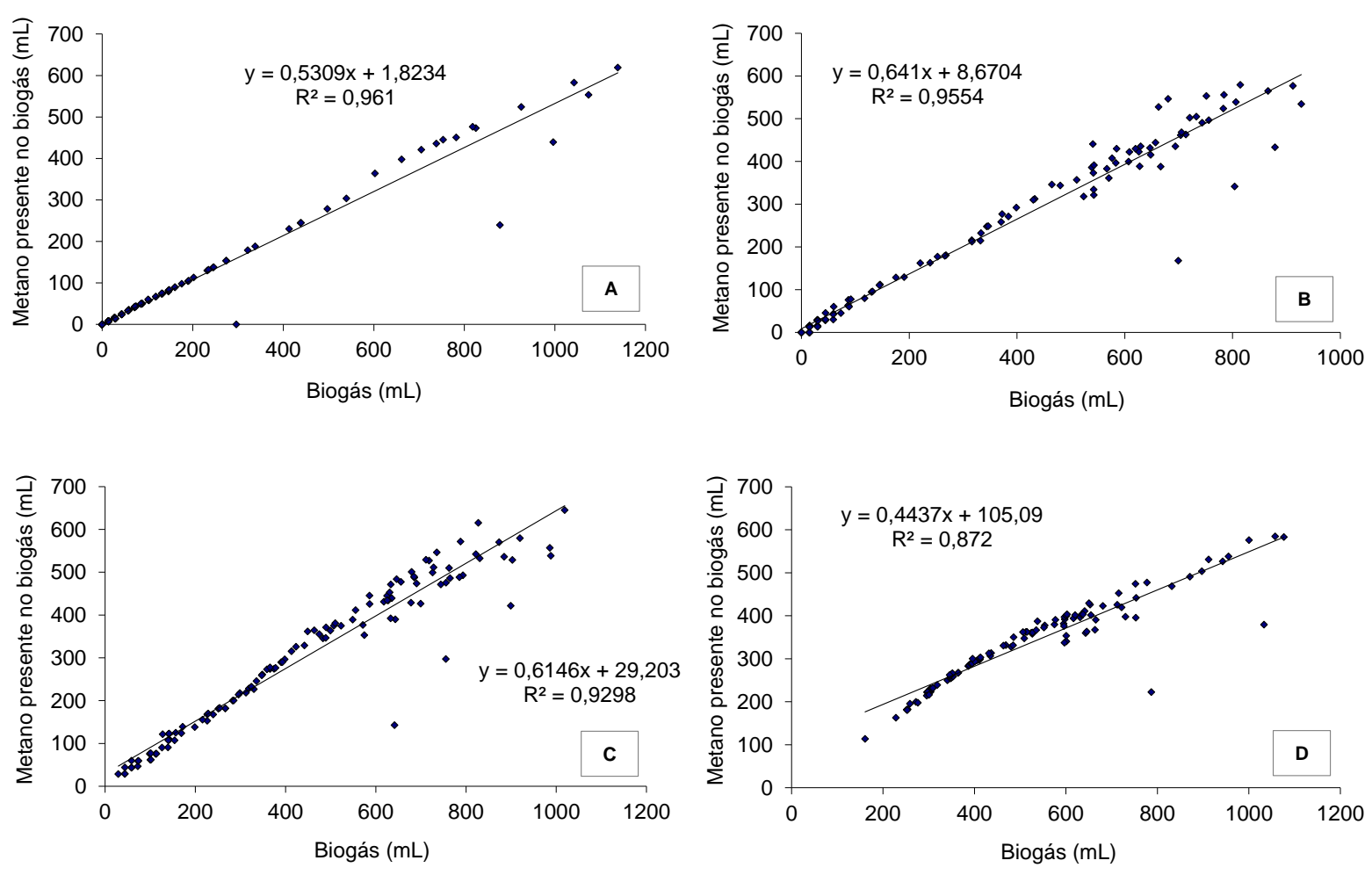

Figura 6: Distribuição de Pearson das amostras 0\% OB (A), 2,5\% OB (B), 5,0\% OB (C) e 7,5\% OB (D).

Evidencia-se na Figura 6 que quanto maior a concentração de óleo adicionado ao processo anaeróbio, menor é a correlação entre o volume de biogás e de metano, mas que mesmo assim essa correlação caracteriza-se como fortemente positiva.

\section{Conclusões}

Conclui-se que a co-digestão anaeróbia de óleo de babaçu associada a resíduos agrícolas obteve melhor rendimento de biogás e de metano com a dosagem de 7,5\% de OB, o qual foi de $285 \%$ e $341 \%$, respectivamente. Além disso, este percentual de OB obteve maior remoção da relação $\mathrm{C} / \mathrm{N}$ quando comparado aos demais percentuais de $\mathrm{OB}(2,5 \%$ e $5,0 \%)$, o que indica que o tratamento $7,5 \%$ OB apresentou melhor estabilização da matéria orgânica.

\section{Referências}

Anderson, G.K., Yang, G. (1992). Determination of bicarbonate and total volatile acid concentration in anaerobic digesters using a simple titration. Water Environment Research, v. 64, pp. 53-59.
ANEEL. Agência Nacional de Energia Elétrica (2015). Banco de Informações de Geração. Disponível em: <www.aneel.gov.br > Acesso em: 15/08/2015.

AOAC. Association of Official Analytical Chemistry. Official methods of analysis. (1995). $6^{\mathrm{a}}$ ed. Arlington: AOAC Intenational.

ARAUTERM. (2015). Poder Calorífico Inferior. Óleo de Babaçu. Disponível em: $<w w w$.arauterm.com.br/pdf/tabela_pc_inferi or.pdf $>$. Acesso em: 15/08/2015.

Astals, S., Nolla-Ardèvol, V., Mata-Alvarez, J. (2012). Anaerobic co-digestion of pig manure and crude glycerol at mesophilic conditions: Biogas and digestate. Bioresource Technology, v. 110, pp. 63-70.

Börjesson, P., Berglund, G. (2006). The prospects for willow plantations for wastewater treatment in Sweden. Biomass and Bioenergy, v.30 (5), pp.428-438.

CENBIO. (2003). Centro Nacional de Referência em Biomassa. Relatório Projeto GASEIFAZMAZ, São Paulo.

Fountoulakis, M.S., Petousi, I., Manios, T. (2010). Co-digestion of sewage sludge with glycerine 
to boost biogas production. Waste Management, v. 30, pp. 1849 - 1853.

Gelegenis, J.; Georgakakis, D.; Angelidaki, I.; Christopoulou, N.; Goumenaki, M. (2007). Optimization of biogas production from olive-oil mill wastewater, by codigesting with diluted poultry-manure. Applied Energy, v.84, pp.646-663.

Halliday, D., Resmick, R., Walker, J. Fundamentos de Física. (2009). 2 ${ }^{\underline{a}}$ ed. Rio de Janeiro: LTC.

Kivaisi, A.K., Mtila, M. Production of biogas from water hyacinth (Eichhornia crassipes) (Mart) (Solms) in a two stage bioreactor (1998). World J. Microbiol. Technol., V. 14, pp. 125-131.

Konrad, O., Lumi, M., Heberle, A.N.A., Tonetto, J.F., Casaril, C.E. (2013). A influência da codigestão de óleo vegetal residual na geração de biogás por lodo de estação de tratamento de efluentes. Revista Brasileira de Energias Renováveis, v.2, pp.1-20.

Konrad, O., Koch, F.F., Lumi, M., Tonetto, J., Bezama, A. (2014). Potential of biogas production from swine manure supplemented with glycerine waste. Eng. Agríc. Jaboticabal, v.34, n.5, pp.844-853.

Ma, J., Van Wambeke, M., Carballa, M., Verstraete, W. (2007). Improvement of the anaerobic treatment of potato processing wastewater in a UASB reactor by codigestion with glycerol. Biotechnology Lett., v. 30, pp. 861-867.

Mata-Alvarez, J., Dosta, J., Macé, S., Astals, S. Codigestion of solid wastes: a review of its uses and perspectives including modelling. (2011). Crit. Rev. Biotechnol., v.31 (2), pp. 99111.

Mata-Alvarez, J., Macé, S., Llabrés, P. Anaerobic digestion of organic solid wastes. An overview of research achievements and perspectives. (2000). Bioresource Technology, v. $74(1)$, pp. 3-16.

Mora-Naranajo, N., Meima, J.A., Haarstrick, A., Hempel, D.C. Modelling and experimental investigation of environmental influences on the acetate and methane formation in solid waste. (2004). Waste Management, v. 24, pp. 9.763-773.

Moret, A.S. (2004). Desafios ao setor elétrico de Rondônia, como a biomassa sustentável pode contribuir para o aumento da oferta de eletricidade: o caso dos resíduos agrícolas. In: Congresso Brasileiro de Planejamento Energético, Itajubá, MG.

Moret, A.S., Guerra, S.M.G. (2012). Geração de eletricidade e qualidade de vida: Análise de um sistema aplicado. Revista Desarrollo Local Sostenible, vol. 5, no 14 .

Mshandete, A., Kivaisi, M., Rubindamayugi, M., Mattiasson, B. Anaerobic batch co-digestion of sisal pulp and fish wastes. (2004). Bioresource Technology, v.95, pp. 19-24.

Neves, L., Oliveira, R., Alves, M.M. Co-digestion of cow manure, food waste and intermittent input of fat. (2009). Bioresource Technology, v. 100, pp. 1957-1962.

Noleto, R.A. (2012). A Política Nacional da Sociobiodiversidade e a Cadeia do Babaçu. Manual Tecnológico de Aproveitamento Integral do Fruto e da Folha do Babaçu. Brasília, DF, $2^{\underline{a}}$ ed.

Pommier, S., Chenu, D., Quintard, M., Lefebvre, $X$. A logistic model for the prediction of the influence of water on the solid waste methanization in landills. (2007). Biotechnology and Bioengineering, v, 97(3), pp. 473-482.

Razaviarani, V., Buchanan, I.D., Malik, S., Katalambula, H. Pilot scale anaerobic codigestion of municipal wastewater sludge with biodiesel waste glycerine. (2013). Bioresource Technology, v. 133, pp. 206-212.

PHA/AWWA. Standard Methods for Water and Wastewater Examination. (1995). 19th ed.

Rizzo, L.G.P., Pires, M.C. Exaustão do modelo fóssil e a busca de alternativas. (2005). Revista de Economia e RI, v.3(6).

Saidu, M., Yuzir, A., Salim, M.R., Salmiati., Azman, S., Abdullah, N. Biological pretreated oil palm mesocarp fibre with cattle manure for biogas production by anaerobic digestion during acclimatization phase. (2014). International Biodeterioration \& Biodegradation, v.95, pp.189-194. 
Silvestre, G., Fernández, G., Bonmati, A. Addition of crude glycerine as strategy to balance the $\mathrm{C} / \mathrm{N}$ ratio on sewage sludge thermophilic and mesophilic anaerobic codigestion. (2015). Bioresource Technology, v. 193, pp. 377-385.

Sun, Y., Wang, D., Yan, J., Qiao, W., Wang, W., Zhu, T. Effects of lipid concentration on anaerobic co-digestion of municipal biomass wastes. (2014). Waste Management v. 34, pp. 1025-1034.

Velázquez, S.M.S.G., Santos, S.M.A., Moreira, J.R., Coelho, S.T. Geração de Energia Elétrica em Comunidades Isoladas na Amazônia a partir de Biomassa Sustentável: Projeto ENERMAD. Disponível em $<$ http://cenbio.iee.usp.br/download/publicaco es/xiiicbe_enermad.pdf> Acesso em: 22 out. 2014.

Zhang, C., Xiao, G., Peng, L., Su, H.,Tan, T. The anaerobic co-digestion of food waste and cattle manure. (2013). Bioresource Technoogy, v. 129, pp. 170-176. 